\title{
Microorganismos del suelo y su efecto sobre la disponibilidad y absorción de nutrientes por las
} plantas

\author{
Nelson Walter Osorio Vega \\ Docente, Facultad de Ciencias Universidad Nacional de Colombia, \\ Cómo citar: \\ Sede Medellín. \\ Osorio-Vega, N. W. (2009). Microorganismos del suelo y su efecto sobre la disponibilidad y absorción de \\ nutrientes por las plantas. En Sociedad Colombiana de la Ciencia del Suelos \& Centro Nacional de \\ Investigaciones de Café (Eds.), Materia orgánica biología del suelo y productividad agrícola: Segundo \\ seminario regional comité regional eje cafetero (pp. 43-71). Cenicafé. \\ https://doi.org/10.38141/10791/0003 3
}

\section{INTRODUCCIÓN}

El objetivo de este documento es presentar algunas funciones de los microorganismos del suelo, los efectos que ejercen sobre la nutrición de las plantas y algunas interacciones entre ellos y su ambiente. En este texto se hace énfasis en el ciclo de nutrientes y en los efectos benéficos de los microorganismos de la rizosfera sobre la nutrición de las plantas. Las condiciones ambientales de la rizosfera y la micorrizosfera también son discutidas, ya que es allí donde ocurren las interacciones entre planta y microorganismos. En general, las plantas pueden liberar carbohidratos, aminoácidos, lípidos, vitaminas, entre otros materiales, a través de sus raíces para estimular los microorganismos en el suelo. El volumen de suelo afectado por estos exudados de la raíz es aproximadamente de $2 \mathrm{~mm}$ desde la superficie de la raíz, y es llamado rizosfera. Los microorganismos de la rizosfera participan en el ciclaje geoquímico de los nutrientes y determinan su disponibilidad para las plantas y la comunidad microbial del suelo. Por ejemplo, en la rizosfera hay organismos capaces de fijar $\mathrm{N}_{2}$ formando estructuras especializadas (p.e Rhizobium y géneros relacionados) o simplemente estableciendo relaciones asociativas (p.e. Azospirillium, Acetobacter). De otro lado, las bacterias amonificantes y nitrificantes son responsables de la conversión de compuestos de $\mathrm{N}$ orgánico a formas inorgánicas $\left(\mathrm{NH}_{4}^{+}\right.$y $\left.\mathrm{NO}_{3}{ }^{-}\right)$, las cuales son disponibles para las plantas. Los microorganismos de la rizosfera pueden también disolver minerales insolubles que controlan la disponibilidad de algunos elementos como el fósforo (P) (tanto nativo como aplicado) a través de la liberación de algunos ácidos orgánicos. Otros microorganismos pueden producir fosfatasas que actúan sobre el $\mathrm{P}$ orgánico. La disponibilidad de $\mathrm{S}$, Fe y Mn está también afectada por las reacciones redox, llevadas a cabo por bacterias de la rizosfera. Igualmente, agentes quelatantes pueden controlar la disponibilidad de micronutrientes y participar en mecanismos de biocontrol de patógenos de plantas. Debido a éstos y otros beneficios sobre el crecimiento 
de las plantas, algunas bacterias de la rizosfera han sido llamadas Rizobacterias Promotoras del Crecimiento de las Plantas (PGPR, por su sigla en inglés). Los beneficios de las PGPR también han sido obtenidos e incluso aumentados, en presencia de hongos formadores de micorrizas, los cuales por sí solos son importantes en el proceso de absorción de nutrientes de baja difusividad (particularmente P). El término "micorrizosfera" se ha usado para describir la parte del suelo que incluye la rizosfera afectada por los exudados de las hifas de los hongos micorrizales.

\section{MICROORGANISMOS DEL SUELO}

El suelo en sí es un ecosistema muy complejo, éste podría ser considerado como un microcosmos donde minerales y materia orgánica (viva o muerta), el agua y el aire, comparten un espacio de gran actividad físico-química. El suelo es una combinación de fases que interactúan íntimamente entre ellas en un sistema que no tiene comparación. Tal complejidad puede ser percibida por la heterogeneidad de estos componentes minerales y las diversas propiedades físico-químicas que se generan, lo cual varía debido al grado de meteorización del suelo. De manera similar, la materia orgánica es heterogénea, porque puede tener múltiples orígenes y diferentes estados de descomposición.

En un ambiente complejo, su población de habitantes no es menos compleja. Dentro de la población microbial se tienen bacterias, actinomicetos, cianobacterias, hongos, algas, protozoarios y virus. En general, los microorganismos más abundantes en el suelo son las bacterias, aunque los hongos (por su mayor tamaño) representan alrededor del $70 \%$ de la biomasa. Torsvik et al. (1990) afirmaron que en un gramo de suelo pueden encontrarse 10.000 especies diferentes de microorganismos, muchos de ellos no conocidos, debido a que no pueden ser cultivados. Tal diversidad es también complementada con una alta densidad de microorganismos. En general, en un gramo de suelo seco es posible encontrar $10^{6}-10^{8}$ bacterias, $10^{6}-10^{7}$ actinomicetos y $10^{4}-10^{5}$ hongos. Otros tipos de microorganismos como algas y protozoos, varían entre $10^{3}-10^{6}$, y $10^{3}-10^{5}$, respectivamente. Además, la rizosfera, volumen de suelo cerca a las raíces que es afectada por las sustancias orgánicas que aquellas raíces liberan, es más poblada que el resto del suelo. Lazarovitz y Nowak (1997) afirman que desde la perspectiva microbiana, el suelo es un desierto en comparación al ambiente nutritivo de la rizosfera.

Los microorganismos del suelo son entidades que influencian varios aspectos del suelo y cada uno desempeña diferentes actividades. De particular interés son aquellos microorganismos involucrados en la descomposición de la materia orgánica y el ciclo de nutrientes. Así, en muchos casos, los microorganismos del suelo pueden determinar la disponibilidad de nutrientes y por eso se consideran herramientas para el manejo del suelo y la nutrición de la planta.

La actividad microbial del suelo es bastante diversa y hace parte de los ciclos biogeoquímicos de varios elementos ( $C, N, O, P$ y S, entre otros). Como actividades específicas en el suelo se incluyen la descomposición de la materia orgánica y de materiales orgánicos adicionados a éste, la fijación de $\mathrm{N}_{2}$ atmosférico, la descomposición de minerales primarios, la 
mineralización del N-orgánico (nitrificación), la solubilización de P, la oxidación de $\mathrm{S}$, la producción de antibióticos, la formación de asociaciones simbióticas para mejorar la captación de nutrientes por parte de las plantas, la protección de plantas contra patógenos, la descomposición de contaminantes (bioremediación), etc. Es importante considerar que de acuerdo a la forma en que obtienen el carbono (C) y la energía, los organismos se clasifican en heterótrofos, autótrofos y fotótrofos. Los heterótrofos obtienen el C y la energía de la oxidación de materiales orgánicos. Los autótrofos obtienen el $\mathrm{C}$ del $\mathrm{CO}_{2}$ y la energía de la oxidación de sustancias inorgánicas. Los fotoautotrófos obtienen el $\mathrm{C}^{2}$ del $\mathrm{CO}_{2}$ y la energía de la luz solar.

La presencia de microorganismos en el suelo es variable, pero sigue la tendencia que a mayor profundidad se disminuye la cantidad de éstos. La razón para ello es que buena parte de los microorganismos que se aíslan en medio de cultivos agarizados son heterótrofos y aeróbicos, y con la profundidad los compuestos carbonáceos y el $\mathrm{O}_{2}$ disminuyen. En consecuencia, la densidad de las poblaciones microbiales disminuye (Figura 1).

Igualmente, los tipos de microorganismos varían entre suelos, para ilustrar este punto se presenta la Tabla 1. Las razones de tales variaciones están en las diferencias de $\mathrm{pH}$, clima, vegetación, disponibilidad de nutrientes, mineralogía y, muy particularmente, con el tipo y cantidad de materia orgánica.
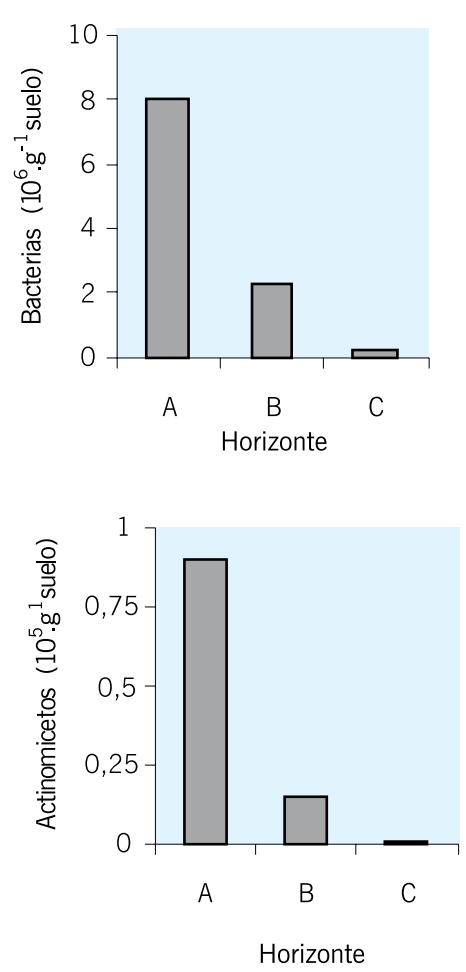

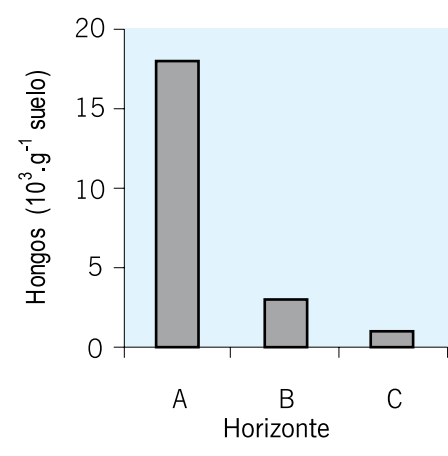

Figura 1. Presencia de microorganismos del suelo en diferentes horizontes de un Inceptisol del Suroeste antioqueño. Fuente: Lab. Microbiología del Suelo, Universidad Nacional de Colombia. 
Tabla 1. Presencia de microorganismos en el horizonte A de suelos del trópico (unidades formadoras de colonia, UFC, por g de suelo seco). Fuente: Lab. Microbiología del Suelo, Universidad Nacional de Colombia.

\begin{tabular}{lrcc}
\multicolumn{1}{c}{ Suelo } & Bacterias & Actinomicetos & Hongos \\
Oxisol (Hawai) & $54 \times 10^{6}$ & 700 & $6,8 \times 10^{4}$ \\
Andisol (Colombia) & $5 \times 10^{6}$ & $15 \times 10^{4}$ & $3,5 \times 10^{5}$ \\
Mollisol (Colombia) & $120 \times 10^{6}$ & $30 \times 10^{5}$ & $3,0 \times 10^{4}$ \\
\hline
\end{tabular}

\section{RIZOSFERA}

La rizosfera es la región del suelo que rodea la superficie de la raíz y que está afectada por los exudados que ésta libera. Fue descrita por primera vez por Hiltner (1904). Hay diferentes tipos de sustancias que se liberan desde las raíces y que estimulan la actividad microbial, como son los carbohidratos (azúcares y oligosacáridos), ácidos orgánicos, vitaminas, nucleótidos, flavonoides, enzimas, hormonas y compuestos volátiles. El resultado es una densa y activa población microbial, que interactúa con las raíces y aún dentro de ellas. El efecto de la rizosfera sobre la población microbial puede ser medido al comparar la densidad de la población (unidades formadoras de colonias, UFC) entre la rizosfera $(R)$ y en el resto del suelo no rizosférico (S), para lo cual se utiliza la "relación $\mathrm{R} / \mathrm{S}$ ". El efecto de la rizosfera es más alto para las bacterias que para los hongos (Tabla 2) y aún más alto para algunos grupos funcionales de bacterias (p.e., amonificantes, denitrificantes). En contraste, las algas exhiben mayor densidad poblacional en el suelo no rizosférico que en la rizosfera. El tipo de plantas puede también afectar la relación R/S, lo cual está asociado con la cantidad y tipo de exudados de la raíz (Tabla 3).

También hay diferencias entre la densidad de población en la superficie de la raíz (rizoplano) y el suelo de la rizosfera. Aunque sobre el rizoplano hay numerosos microorganismos, se estima que sólo 4-10\% de su área de superficie total está en contacto

Tabla 2. Número de microorganismos (UFC.g-1 suelo) en la rizosfera (R) de trigo (Triticum aestivum L.) y en el suelo el no-rizosférico (S) y su relación R/S (modificado de Gray y Williams, 1971).

\begin{tabular}{llcc}
\multicolumn{1}{c}{ Microorganismos } & Rizosfera & Suelo no-rizosférico & Relación R/S \\
Bacterias & $1,2 \times 10^{9}$ & $5,3 \times 10^{7}$ & 23 \\
Actinomicetos & $4,6 \times 10^{7}$ & $7,0 \times 10^{6}$ & 7 \\
Hongos & $1,2 \times 10^{6}$ & $1,0 \times 10^{5}$ & 12 \\
Protozoos & $2,4 \times 10^{3}$ & $1,0 \times 10^{3}$ & 2 \\
Algas & $5,0 \times 10^{3}$ & $2,7 \times 10^{4}$ & 0,2 \\
Amonificadores & $5,0 \times 10^{8}$ & $4,0 \times 10^{6}$ & 125 \\
Denitrificadores & $1,26 \times 10^{8}$ & $1,0 \times 10^{5}$ & 1.260 \\
\hline
\end{tabular}


Tabla 3. Número de bacterias (UFCX $10^{6} \cdot \mathrm{g}^{-1}$ suelo o masa seca de raíz) en el rizoplano y rizosfera de diferentes plantas, y en el suelo no-rizosférico (S) y su relación R/S. Fuente: Rouat y Katznelson (1961).

\begin{tabular}{lllll}
\multicolumn{1}{c}{ Planta } & Rizoplano & Rizosfera & $\begin{array}{c}\text { Suelo no } \\
\text { rizosférico }\end{array}$ & \multicolumn{1}{c}{$\begin{array}{c}\text { Relación } \\
\text { R/S }\end{array}$} \\
\hline Trébol Rojo (Trifolium pratense) & 3.844 & 3.255 & 134 & 24 \\
Avena (Avena sativa) & 3.588 & 1.090 & 184 & 6 \\
Lino (Linum usitatissum) & 2.450 & 1.015 & 184 & 5 \\
Trigo (Triticum aestivum) & 4.119 & 710 & 120 & 6 \\
Maíz (Zea mays) & 4.500 & 614 & 184 & 3 \\
Cebada (Hordeum vulgare) & 3.216 & 505 & 140 & 3 \\
\hline
\end{tabular}

físico con los microorganismos del suelo. En la literatura no han sido reportadas diferencias en la rizosfera según el tipo de suelo, pero se sospecha que los suelos que exhiben severas limitaciones para el crecimiento microbial (p.e., suelos ácidos y ricos en $\mathrm{Al}$, que abundan en el trópico) pueden presentar relaciones R/S más altas para las bacterias y otros microorganismos.

La extensión de la rizosfera varía con la planta y el suelo, pero es aceptado que cubre al menos $2 \mathrm{~mm}$ desde el rizoplano. Algunos autores han mostrado que la zona de influencia puede ser al menos de $10 \mathrm{~mm}$ (Tabla 4). La diversidad de microorganismos es también variable, cerca al rizoplano hay una comunidad diversa pero al aumentar la distancia desde el rizoplano la diversidad se reduce. Papavizas y Davey (1961) encontraron efectos similares sobre actinomicetos y hongos de la rizosfera, esto parece estar asociado con la concentración de carbono en la solución del suelo (exudados de las raíces), la cual disminuye desde el rizoplano.

La liberación de exudados de la raíz puede estar afectada por varios factores en la planta, el suelo y el ambiente. De acuerdo con Bowen y Rovira (1999), las plantas pueden liberar entre $10-30 \%$ de fotosintatos a través del sistema de raíces. Whipps y Lynch (1986) encontraron que un mismo factor (p.e., estrés por agua, bajo pH, químicos aplicados al follaje) produce incremento o disminución en la liberación de compuestos orgánicos en

Tabla 4. Número de bacterias en función de la distancia desde la superficie de la raíz. Fuente: Paul y Clark (1989).

\begin{tabular}{lcc}
\hline \multicolumn{1}{|c}{ Distancia $(\mathrm{mm})$} & UFC $\times \mathbf{1 0}^{9} . \mathrm{cm}^{-3}$ suelo & Tipos morfológicos \\
\hline $0-1$ & 120 & 11 \\
$1-5$ & 96 & 12 \\
$5-10$ & 41 & 5 \\
$10-15$ & 34 & 2 \\
$15-20$ & 13 & 2 \\
\hline
\end{tabular}


diferentes plantas. Las raíces también secretan mucílagos polisacáridos y pierden capas de células en la punta de la raíz al crecer a través del suelo, y así se liberan más compuestos carbonáceos a la rizosfera.

Las condiciones fisicoquímicas que predominan en la rizosfera se pueden usar para entender el papel que juegan los microorganismos sobre la disponibilidad de nutrientes. Por ejemplo, la concentración de oxígeno $\left(\mathrm{O}_{2}\right)$ en la rizosfera es muy baja debido a la alta demanda requerida para la respiración microbial a partir de compuestos carbonáceos y a la alta densidad microbial. Consecuentemente, la concentración de $\mathrm{CO}_{2}$ es alta. Estas condiciones crean un ambiente anaeróbico, y se favorecen las reacciones de reducción. En la Tabla 1 se muestra que las bacterias denitrificantes (anaeróbicas) tienen una relación R/S más alta (1260), lo cual facilita la reducción de algunos elementos tales como N, S, Fe y $\mathrm{Mn}$.

El pH de la rizosfera usualmente es de 1-2 unidades más bajo que el del suelo. Varios mecanismos son responsables de este efecto: (i) producción de $\mathrm{CO}_{2}$ por procesos de respiración que forman $\mathrm{H}_{2} \mathrm{CO}_{3}$, (ii) actividad de las bombas de $\mathrm{H}^{+}$en la obtención de nutrientes por las plantas y los microorganismos, (iii) liberación de ácidos orgánicos por raíces y microorganismos, (iv) descomposición de la materia orgánica y (v) fijación de $\mathrm{N}_{2}$ por la simbiosis Rhizobium-leguminosa. Los efectos también pueden variar con la capacidad buffer del suelo y el tipo de planta involucrada. Las condiciones ácidas favorecen la solubilización de minerales del suelo (p.e., fosfatos de calcio). Las características de la rizosfera varían con la especie de planta y las condiciones del suelo. La rizosfera de plantas de arroz de inundación exhibe un ambiente más aeróbico que el resto del suelo. Esto es porque el tejido aerénquima de las plantas de arroz permite el transporte de $\mathrm{O}_{2}$ a las raíces y su liberación a la rizosfera. Esto facilita la oxidación de Fe y Mn que tienden a incrementar su disponibilidad a niveles que llegan a ser tóxicos para las plantas, dadas las condiciones reductoras de los suelos inundados.

\section{RIZOBACTERIAS PROMOTORAS DEL CRECIMIENTO VEGETAL (PGPR)}

Las bacterias de la rizosfera pueden aumentar el crecimiento de las plantas y el rendimiento de los cultivos por diferentes vías. El acrónimo PGPR (por sus siglas en inglés) ha sido ampliamente usado para agrupar estos microorganismos. Recientemente se ha propuesto dividir los PGPR en dos categorías: Biocontrol-PGPR y PGPR. Se afirma que esta separación es importante para diferenciar los mecanismos empleados por estas bacterias para promover el crecimiento de las plantas. Biocontrol-PGPR son estrictamente aquellas bacterias que participan en el biocontrol de patógenos de plantas, mientras que PGPR son bacterias que cumplen otras funciones diferentes (p.e., nutricional, hormonal). También se sugiere reemplazar el término rizobacteria por simplemente bacteria, porque algunas bacterias pueden promover el crecimiento de las plantas pero no son habitantes de la rizosfera.

\section{Efectos sobre la solubilidad del manganeso}

La disponibilidad de $\mathrm{Mn}$ en la rizosfera está afectada por las condiciones redox y el pH del suelo. En suelos oxidados el $\mathrm{Mn}$ está presente en su forma oxidada, $\mathrm{Mn}^{4+}$, en el mineral de baja solubilidad llamado Pirolusita $\left(\mathrm{MnO}_{2}\right)$. Algunas bacterias de la rizosfera (Bacillus, 
Pseudomonas, Geobacter) pueden reducir el $\mathrm{Mn}$ oxidado de $\mathrm{Mn}^{4+}$ a $\mathrm{Mn}^{2+}$ que es la forma química metabólicamente usada por las plantas. La reacción es como sigue:

$$
\mathrm{MnO}_{2}+4 \mathrm{H}^{+}+2 \mathrm{e}^{-} \leftrightarrow \mathrm{Mn}^{2+}+2 \mathrm{H}_{2} \mathrm{O}
$$

En esta reacción son importantes dos puntos, en primer lugar la reducción de Mn requiere electrones y protones. Los electrones son suministrados por la descomposición de compuestos carbonáceos y los protones pueden ser suministrados por el sistema de excreción de protones de las células de las raíces. Consecuentemente, la actividad de reductores de $\mathrm{Mn}$ es altamente favorecida en la rizosfera. Las aplicaciones de materia orgánica también pueden favorecer la reducción de Mn. En suelos alcalinos donde el Mn es usualmente insoluble, el efecto de la rizosfera es benéfico, pero en suelos ácidos con abundancia de minerales de Mn la excesiva reducción de Mn puede inducir a la toxicidad por este elemento, en plantas sensibles. Arines y otros (1992) encontraron que la micorrizosfera puede disminuir la actividad de microorganismos reductores de $\mathrm{Mn}$ y favorecer la oxidación del Mn, lo cual podría ser conveniente para el manejo de suelos ricos en $\mathrm{Mn}$.

El Mn juega un papel importante en la resistencia de las plantas a las enfermedades. Este elemento, así como el Cu, es requerido para la síntesis de lignina, la cual incrementa la resistencia de los tejidos de las raíces a la penetración de patógenos; consecuentemente, se espera que las plantas deficientes en Mn sean más susceptibles al ataque de patógenos. Gaeumannomyces graminis, como muchos otros hongos patógenos del suelo, es un potente oxidante de Mn que dañaría la lignificación de las raíces en los sitios de infección. Los reductores de Mn efectivos de la rizosfera (p.e., Pseudomonas sp.) pueden tener efectos benéficos no solo sobre la nutrición de las plantas sino también como biocontroladores de patógenos.

Adicionalmente, las raíces y las bacterias de la rizosfera pueden producir agentes quelatantes (compuestos fenólicos, ácidos orgánicos), capaces de formar complejos solubles con el Mn y otros elementos y así evitar la reprecipitación del Mn.

En contraste, en los suelos inundados donde la disponibilidad del $\mathrm{Mn}^{2+}$ puede ser alta, la oxidación de Mn por bacterias de la rizosfera favorecería el crecimiento de las plantas. Las raíces de arroz liberan $\mathrm{O}_{2}$ a la rizosfera evitando así los efectos tóxicos por Mn.

\section{Efectos sobre la solubilidad del hierro}

La dinámica del Fe en la rizosfera es muy similar a la del Mn. El Fe del suelo está presente en formas oxidadas como $\mathrm{Fe}^{3+}$, como un componente de la estructura de minerales insolubles como goetita $(\mathrm{FeOOH})$ o hematita $\left(\mathrm{Fe}_{2} \mathrm{O}_{3}\right)$. Las bacterias de la rizosfera (Bacillus, Pseudomonas, Geobacter, Alcaligenes, Clostridium, y Enterobacter) pueden reducir Fe ${ }^{3+}$ a $\mathrm{Fe}^{2+}$, la forma requerida por las plantas. Los electrones y protones están disponibles en la rizosfera y consecuentemente, el Fe es reducido, sin embargo éste puede ser reprecipitado. Las reacciones de reducción son:

$$
\mathrm{FeOOH}+3 \mathrm{H}^{+}+\mathrm{e}^{-} \leftrightarrow \mathrm{Fe}^{2+}+2 \mathrm{H}_{2} \mathrm{O}
$$




$$
\mathrm{Fe}_{2} \mathrm{O}_{3}+6 \mathrm{H}^{+}+2 \mathrm{e}^{-} \leftrightarrow 2 \mathrm{Fe}^{2+}+3 \mathrm{H}_{2} \mathrm{O}
$$

En condiciones de deficiencia de $\mathrm{Fe}$, algunas bacterias de la rizosfera, particularmente Pseudomonas fluorescentes, producen agentes quelatantes (sideróforos) que forman con $\mathrm{Fe}^{2+}$ complejos solubles disponibles para estas bacterias. Scher (1986) encontró en suelos supresivos para el hongo Fusarium oxysporium, que la bacteria Pseudomonas putida produjo un sideróforo que capturó el Fe. El complejo sideróforo-Fe puede ser usado por $P$. putida pero no por $F$. Oxysporium, que requiere Fe para sintetizar enzimas que degradan las paredes celulares de la planta. Bajo este sistema la bacteria es un buen agente de control biológico. Sin embargo, al aplicar Fe-EDTA (un fertilizante de Fe), el mecanismo de control sobre $F$. oxysiporium desapareció, ya que este hongo puede usar este fertilizante como fuente de Fe. Un fuerte agente quelante de Fe, por ejemplo EDDA, aumentaría el efecto de P. putida. Van Peer et al. (1990) encontraron efectos similares con EDDHA. De nuevo, los mecanismos relacionados con efectos nutricionales participan en el biocontrol de plantas patógenas.

Por otra parte, el Fe es un componente del grupo "hemo" en las enzimas catalasas y peroxidasas, las cuales son requeridas en la síntesis de lignina. La lignificación de las paredes celulares es una respuesta común de las plantas cuando son desafiadas por fitopatógenos. Aquellas plantas deficientes en Fe pueden ser más vulnerables a los patógenos que aquellas bien abastecidas con el nutriente. En la Tabla 5 se presentan los efectos de la rizosfera sobre el $\mathrm{pH}$ y la disponibilidad de Fe, Mn y $\mathrm{Zn}$ en suelo y en la rizosfera.

\section{OXIDACIÓN DEL AZUFRE}

La presencia de azufre como ión sulfato $\left(\mathrm{SO}_{4}{ }^{2-}\right)$ es también el resultado de la actividad bacterial en el suelo. Existen bacterias (Thiobacioluus oxidans) que son capaces de oxidar el $\mathrm{S}$ elemental o sulfuros, y producir ácido sulfúrico $\left(\mathrm{H}_{2} \mathrm{SO}_{4}\right)$, el cual al disociarse libera el ión $\mathrm{SO}_{4}{ }^{2-}$ que es la forma química que la planta absorbe. Una vez está en la solución del

Tabla 5. pH del suelo y disponibilidad de micronutrientes (DPTA-extraible, $\mu$ mol. $\mathrm{kg}^{-1}$ de suelo) en el suelo y la rizosfera de lupino blanco (Lupinus albus). Fuente: Dinkelaker et al. (1989).

\begin{tabular}{lcc} 
& Suelo & Rizosfera del suelo \\
$\mathrm{pH}$ & 7,5 & 4,8 \\
$\mathrm{Fe}$ & 34 & 251 \\
$\mathrm{Mn}$ & 44 & 222 \\
$\mathrm{Zn}$ & 2,8 & 16,8 \\
\hline
\end{tabular}

suelo, el ión sulfato puede ser adsorbido sobre los minerales arcillosos o los óxidos e hidróxidos de Fe y Al. Así mismo, el ión sulfato puede precipitarse con otros iones $\left(\mathrm{Fe}^{3+}, \mathrm{Al}^{3+}, \mathrm{K}^{+}, \mathrm{Ca}^{2+}\right)$ para formar compuestos insolubles. En ambos casos se genera un equilibrio químico entre estas especies (precipitadas y adsorbida) y el ión en solución.

$$
\mathrm{S}_{2}+2 \mathrm{H}_{2} \mathrm{O}+3 \mathrm{O}_{2} \rightarrow 2 \mathrm{H}_{2} \mathrm{SO}_{4}
$$

$\mathrm{FeS}+2 \mathrm{O}_{2} \rightarrow \mathrm{FeSO}_{4}$ 
La masiva oxidación de azufre y sulfuros en algunos suelos da origen a los suelos sulfatoácidos. En éstos, el pH puede ser tan bajo (como 2,5), lo cual no sólo restringe el crecimiento vegetal, sino que las aguas del suelo pueden pasar a corrientes de agua y afectar la vida de los peces.

Por otro lado, cuando cae la hojarasca, ésta enriquece la materia orgánica fresca del suelo. La concentración de $\mathrm{S}$ de este material fluctúa alrededor de 0,1-0,3\%. Los microorganismos descomponedores de la materia orgánica liberan enzimas que liberan el $\mathrm{S}$ de los compuestos que lo contienen (R-SH) y, posteriormente, es oxidado para formar sulfato.

\section{FIJACIÓN DE $\mathrm{N}_{2}$}

El $\mathrm{N}$ es uno de los nutrientes más limitativos para el crecimiento de las plantas. Algunas bacterias de la rizosfera tienen la capacidad de fijar $\mathrm{N}_{2}$ en formas orgánicas que pueden ser usadas por las plantas. Las condiciones de la rizosfera favorecen la fijación de $\mathrm{N}_{2}$ porque ésta es llevada a cabo por bacterias heterótrofas que usan compuestos orgánicos como fuente de electrones para la reducción de $\mathrm{N}_{2}$. La reacción simplificada de la fijación de $\mathrm{N}_{2}$, es la siguiente:

$$
\mathrm{N}_{2}(\mathrm{~g})+8 \mathrm{H}^{+}+8 \mathrm{e}^{-}+(15-25 \mathrm{ATP}) \rightarrow 2 \mathrm{NH}_{3}+\mathrm{H}_{2}
$$

Esta reacción de reducción es realizada exclusivamente por algunas bacterias, actinomicetos y cianobacterias. La fijación de $\mathrm{N}_{2}$ la realizan estos microorganismos en forma libre 0 asociados con plantas y hongos, con estos últimos se hace el proceso más eficiente ya que aportan los ATP y electrones (e-) requeridos. Algunas asociaciones simbióticas implican la formación de estructuras especializadas (p.e., nódulos) mientras que otras no forman tales estructuras, pero sí hay intercambio de materiales (p.e., caña de azúcarAcetobacter).

Entre las bacterias fijadoras de $\mathrm{N}_{2}$ se destacan las de los géneros Rhizobium, Bradyrrhizobium, Mesorhizobium, Allorhizobium, Sinorhizobium, y Mesorhizobium, que forman simbiosis con leguminosas. En este caso la concentración de $\mathrm{O}_{2}$ es regulada por la hemoglobina. El suministro de compuestos carbonáceos ocurre en el interior de los nódulos y así se evita la competencia con otros microorganismos. Ésta es sin duda la interacción entre planta y bacteria más estudiada.

Otro fijador de $\mathrm{N}_{2}$ es Azotobacter paspali, el cual crece en la rizosfera de pasturas tropicales tales como Paspalum notatum c.v. batatais y Digitaria sp., con las cuales exhibe cierto grado de especificidad. Aunque la fijación de 5-25 kg.ha-1. $a n ̃ 0^{-1}$ de N es ampliamente aceptada, valores tan altos como $90 \mathrm{~kg}$. ha ${ }^{-1}$. año-1 de N han sido reportados. Acetobacter diazotrophicus es otro fijador de $\mathrm{N}_{2}$ que puede crecer dentro del tejido de la raíz ('endorrizosfera') de la caña de azúcar, incluyendo tejidos vasculares donde puede alcanzar una densidad poblacional de $10^{6}$ células/g de estos tejidos. Por su particular localización, A. diazotrophicus tiene la ventaja de obtener carbono sin la competencia microbial y 
aparentemente puede tolerar una concentración de $\mathrm{O}_{2}$ más alta que otras bacterias. La caña de azúcar puede obtener 100-150 kg.ha-1 de N de esta asociación (Tabla 6).

Una de las simbiosis asociativas más estudiadas es la formada por Azospirillum spp. y las raíces de numerosas gramíneas, incluyendo cultivos de cereales importantes. Se han reportado incrementos en el crecimiento y rendimiento de las plantas del $5 \%$ al $30 \%$. Los

Tabla 6. Valores de fijación de $\mathrm{N}_{2}$ por bacterias en diferentes sistemas (libre, asociativo o simbiótico). Fuente: Foth y Ellis (1996).

\section{Sistema biológico}

Microorganismos vida libre

Cianobacteria 25

Azotobacter

0,3

Clostridium pasteurianum

$0,1-0,5$

Pastos-simbiosis asociativa $5-25$

Caña de azúcar-Acetobacter diazotrophicus Paspalum notatum-Azotobacter Digitaria spp.-Azotobacter Asociativa

Hasta 90

Planta-cianobacteria

Gunnera

Azolla 313

Líquenes (hongo-cianobacteria)

$39-84$

Simbiosis nodulantes con No-leguminosas

Alnus-Frankia

$40-300$

Casuarina- Francia 58

Simbiosis con leguminosas

Soya-Bradyrhizobium

Alfalfa-Rhizobium $128-600$

Caupí- Rhizobium 84

Trébol- Rhizobium 104-160

Lupino- Rhizobium 150-169

Fijación de $\mathrm{N}_{2}$ de rizobios en simbiosis con algunas leguminosas tropicales Centrosema

Stylosanthes 30-196

Lenteja

Caupí

Soya

Garbanzo 
beneficios parecen deberse a una producción de reguladores de crecimiento de las plantas (auxinas, giberelinas y citoquininas), que estimulan el crecimiento de los pelos radicales, con una mayor obtención de los nutrientes. El efecto favorable no es debido propiamente a la fijación de $\mathrm{N}_{2}$. Bashan et al. (1999) y Carillo-García et al. (2000) han reportado que especies de cactus inoculadas con $A$. brasilense mejoraron su establecimiento y desarrollo en suelos desérticos.

Otras bacterias fijadoras de $\mathrm{N}_{2}$ no simbióticas como Azotobacter chrococcum, Bacillus polymyxa y Clostridium pasteurianum han incrementado el vigor de las semillas de maíz, trigo y tomate, y han promovido una floración más temprana en tomate. Quizá la respuesta también se debió a efectos hormonales y no necesariamente a la fijación de $\mathrm{N}_{2}$.

Respuestas positivas en el crecimiento de las plantas con fijadores de $\mathrm{N}_{2}$ pueden esperarse en suelos donde el suministro de $\mathrm{N}$ es limitado. Por ejemplo, los suelos desérticos (Aridisoles en la taxonomía de suelos del USDA) tienen muy bajos contenidos de materia orgánica y baja disponibilidad de agua, que restringe el crecimiento de las plantas. Los resultados positivos de Bashan et al. (1999) y Carillo-García (2000) soportan esta afirmación. Otro tipo de suelo, por ejemplo, los derivados de cenizas volcánicas, que normalmente presentan baja disponibilidad de $\mathrm{N}$ podrían ser favorables para las bacterias fijadoras de $\mathrm{N}_{2}$. De manera similar, los suelos erosionados que han perdido la materia orgánica de su superficie o que han estado bajo quemas, pueden ser rehabilitados con el crecimiento de plantas al usar bacterias fijadoras de $\mathrm{N}_{2}$.

Cuando se emplean leguminosas, la inoculación con su simbionte (Rhizobium o géneros relacionados) puede mejorar el establecimiento de plantas. Para plantas no-leguminosas, los resultados de la inoculación con fijadores de $\mathrm{N}_{2}$ de vida libre, tales como Azospirillium y Azotobacter, pueden ser inciertos. Resultados exitosos han sido obtenidos cuando estas bacterias de la rizosfera son combinadas con plantas que tienen alta eficiencia en la fotosíntesis (plantas $\mathrm{C}_{4}$ ), así el suministro de $\mathrm{C}$ para estas bacterias heterótrofas podría ser satisfactorio.

\section{Abono verde}

Una aplicación práctica de la fijación de $\mathrm{N}_{2}$ en el manejo de los suelos es el empleo del abono verde. El abono verde consiste en la incorporación de un cultivo en la capa arable

Tabla 7. Efecto de la incorporación de azolla en un suelo sobre el contenido relativo de $\mathrm{N}$ en plantas de maíz. Fuente: Osorio, no publicado.

\section{Tratamiento}

Contenido relativo de $\mathbf{N}(\%)$

Testigo (sin azolla, sin fertilizante)

100

Azolla filiculoides como abono verde (50 kg.ha-1 de N)

Urea (50 kg.ha-1 de N) 
del terreno, para lo cual se prefiere una leguminosa antes de floración (soya, caupí, etc.). La incorporación de leguminosas en el suelo incrementa el contenido de materia orgánica y el suministro de nutrientes, particularmente $\mathrm{N}$, debido a la alta concentración de este elemento en los tejidos vegetales $(\sim 4 \%)$ y a la baja relación C:N ( 10-12). En la Tabla 7 aparece el efecto de la incorporación de azolla como abono verde en el contenido de $\mathrm{N}$ de plantas de maíz .

\section{SIMBIOSIS MICORRIZAL}

El término micorriza fue propuesto para describir la asociación simbiótica que se presenta, de manera natural, entre las raíces del 95\% de las especies vegetales y ciertos hongos del suelo ( $m i c o=$ hongo; rriza=raíz). Es una relación mutualista en la que el hongo coloniza la raíz y proporciona a la planta hospedera agua y nutrientes, que absorbe del suelo a través de su red externa de hifas. La planta por su parte aporta los compuestos carbonados que el hongo utiliza como fuente energética.

La formación de esta simbiosis se constituye es una estrategia exitosa desarrollada por las plantas para superar el estrés que se sucede durante la colonización de ecosistemas terrestres. Existen diferentes tipos de micorrizas, las más estudiadas son la ectomicorrizas y las endomicorrizas. Las ectomicorrizas corresponden a relaciones simbióticas entre hongos Basidiomicetes y Ascomicetes y algunas especies vegetales arbóreas. Las endomicorrizas o micorrizas arbusculares se constituyen en la interacción entre hongos de la clase Glomeromycetes y las raíces de casi el $80 \%$ de todas las especies de plantas terrestres, incluyendo muchas especies de plantas de interés agrícola y hortícola.

Hay evidencia de la presencia de estos hongos desde el período Devónico, hace 398 millones de años, cuando las plantas acuáticas colonizaron la superficie terrestre. Los hongos micorrizo arbusculares (AMF, de sus siglas en inglés) son biotrofos obligados, es decir, que no pueden ser cultivados y multiplicados en ausencia de una planta hospedera. La razón más aceptada es que el hongo durante la larga evolución de la relación simbiótica, perdió su capacidad para fijar carbono o la maquinaria genética para hacerlo, y llegó a ser completamente dependiente de una planta hospedera para obtener fotosintatos. Aunque se considera que el $95 \%$ de las especies vegetales forman asociaciones micorrizales, éstas solo se han examinado en un $3 \%$ de ellas y es aún mucho más incipiente la información acerca de su dependencia por la condición micorrizal.

\section{Funcionamiento de la simbiosis}

Los AMF no tienen un mecanismo de reconocimiento de un grupo taxonómico de plantas en especial y se conoce que aproximadamente 150 especies de AMF colonizan alrededor de 240.000 especies de plantas. Las estructuras infectivas de los AMF, como las esporas e hifas, germinan y entran en contacto con la superficie de las raíces. La penetración de la raíz ocurre vía apresorio, la formación de esta estructura sólo se da en respuesta a exudados radicales producidos por plantas hospederas. Estas señales incluyen una variedad de isoflavonoides y compuestos fenólicos, comunes a otras interacciones plantamicroorganismo. 
Una vez dentro de las raíces, los AMF producen hifas intercelulares, causando cambios sutiles en la estructura de la pared de las células vegetales. Las terminaciones de las hifas penetran la pared de células corticales y se diferencian dentro de ellas para formar los arbúsculos. Aunque la pared celular es atravesada, la membrana plasmática de la célula vegetal permanece sin ser penetrada. Esta membrana se invagina alrededor del arbúsculo dando como resultado la formación de un compartimiento apoplástico y se constituye en la interfase simbiótica. Se asume que esta interfase es el sitio de intercambio de carbono y fosfato entre los simbiontes. Por lo tanto, se considera que el arbúsculo es una estructura clave en la simbiosis. En las asociaciones mutualistas, a diferencia de las asociaciones parasíticas, el transporte de nutrientes es bidireccional.

Es bien documentado el incremento en la captación de nutrientes, principalmente de P, de la solución del suelo por plantas colonizadas con AMF. La captación de P del suelo por los AMF y la subsiguiente translocación y transferencia a la planta huésped permite obtener un nivel equivalente o superior de producción. Los AMF desarrollan una amplia red de hifas extrarradicales alrededor del sistema de raíces de la planta hospedera, lo cual tiene repercusión directa en los aspectos relacionados con la nutrición de la planta. Las hifas externas de los AMF se extienden 10 a $12 \mathrm{~cm}$ desde la superficie de la raíz y captan a su paso nutrientes, esto es particularmente importante para captar nutrientes de difusión limitada (P, Cu, Zn). Las hifas superan la zona de captación de P por parte de la raíz, la cual es de 1 a $2 \mathrm{~mm}$ desde la superficie radical. Se ha reportado que por cada centímetro de raíz colonizada hay en promedio 1 metro de hifas micorrizales; incluso se han reportado valores de 10 a $14 \mathrm{~m}$ de hifas.

Las hifas micorrizales normalmente tienen una mayor afinidad que las raíces para absorber $P$, es decir, que a diferencia de las raíces, las hifas pueden absorber $\mathrm{P}$ a concentraciones muy bajas. Además, debido al pequeño radio de las hifas micorrizales $(1-3 \mu \mathrm{m})$ con respecto al de las raíces $(150 \mu \mathrm{m})$, no se genera un gradiente de concentración de $P$ alrededor de la hifa, lo que significa que no hay una fuerte zona de agotamiento. Smith y Read (1997) reportaron que raíces micorrizadas exhibieron una absorción de P 3 a 5 veces más alta que raíces sin micorrizas.

Se han propuesto mecanismos bioquímicos y fisiológicos para explicar el incremento en el suministro de $\mathrm{P}$ biodisponible por parte de los AMF. Estos mecanismos involucran la acidificación de la rizosfera, el incremento en la actividad fosfatasa de las raíces y la excreción de agentes quelatantes. Sin embargo, lo más aceptado es que la eficiencia de los AMF para la captación de iones fosfato se debe al incremento en el área de suelo explorada por las hifas extrarradicales, por lo que son consideradas una extensión del sistema radical de la planta.

Recientemente se ha encontrado que existen proteínas transportadoras de $\mathrm{P}$ de alta afinidad (HATS), acopladas al gradiente de protones producido por las $\mathrm{H}^{+}$-ATPasas. Estas proteínas se expresan en la rizodermis y pelos radicales, y en las hifas extrarradicales y membranas periarbusculares y se constituyen en sistemas simporte que se expresan a bajas concentraciones de $\mathrm{P}$ en la solución del suelo y permiten la captación eficiente de iones fosfato. Algunos autores han demostrado que la colonización micorrizal puede alterar la expresión de las proteínas transportadoras de $P$ en las plantas. Según Burleign y Harrison (1999) existe una regulación negativa de los transportadores de $P$ en las plantas 


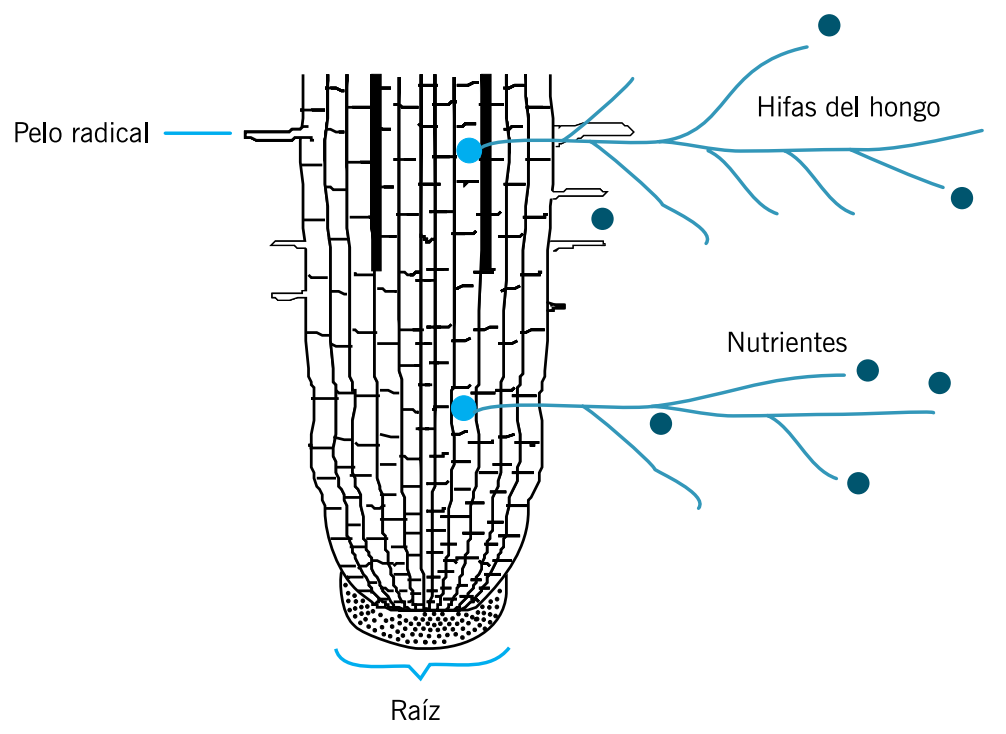

Figura 2. Presencia de hifas micorrizales intra y extrarradicales que captan nutrientes mucho más allá de donde lo obtienen los pelos radicales (dibujo original de N.W. Osorio).

inducida por la colonización micorrizal. Al presentarse una alta concentración de $\mathrm{P}$ en el citoplasma de la célula vegetal (debido a la actividad de los AMF) los transportadores de $\mathrm{P}$ de la membrana celular se inactivan y la absorción de $\mathrm{P}$ recae casi exclusivamente sobre el hongo.

Independientemente de su papel nutricional, la colonización por AMF contribuye significativamente al mejoramiento de la estructura del suelo, incrementa la resistencia de la planta al estrés biótico y abiótico, y favorece el establecimiento de interacciones con otros microorganismos benéficos. La hifa micorrizal también libera compuestos carbonáceos a su alrededor y forma un nicho llamado "micorrizosfera" (Figura 3). Usualmente, los beneficios de los microorganismos de la rizosfera son incrementados en presencia de la simbiosis micorrizal.

\section{Dependencia micorrizal de las plantas}

En algunas especies de plantas la asociación con AMF es indispensable para su crecimiento, sin embargo, el grado de dependencia micorrizal (DM) varía con la especie vegetal. La DM es definida como el grado en el cual una especie de planta depende de la condición micorrizal para alcanzar su máximo crecimiento o producción. Según Plenchette et al. (1983) la DM se determina como el porcentaje de la diferencia entre la producción de masa seca total de plantas inoculadas y no inoculadas sobre la producción total de masa seca de plantas inoculadas. 


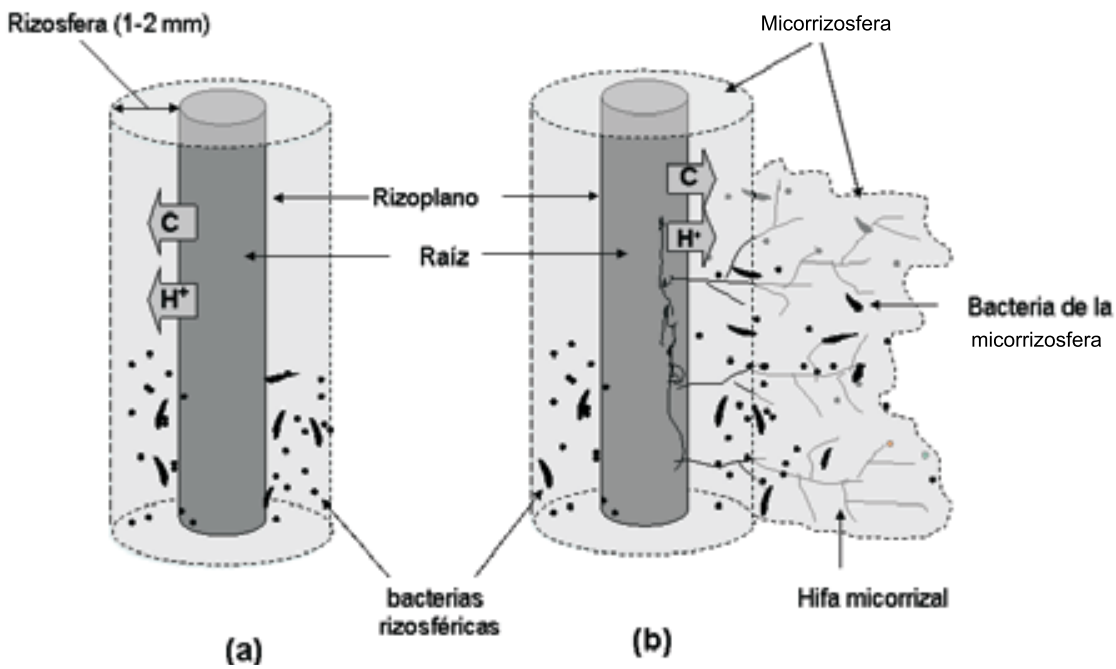

Figura 3. Diagrama que ilustra la rizosfera (a) y la micorrizosfera (b) de las plantas (dibujo original de N.W. Osorio).

$\mathrm{D} \cdot \mathrm{M}=\frac{\text { Masa seca plantas inoculadas }- \text { Masa seca plantas no inoculadas }}{\text { Masa seca plantas inoculadas }} \times 100$

Algunos aspectos como la concentración de $\mathrm{P}$ en la solución del suelo, la morfología de la raíz y el tamaño de la semilla y su contenido de P son factores determinantes para la DM de las plantas. Por ejemplo, las plantas con raíces gruesas, poco ramificadas y con pocos pelos radicales son usualmente más dependientes de la simbiosis micorrizal que las plantas con raíces finas y ramificadas.

Habte y Manjunath (1991) han propuesto clasificar la DM en cinco categorías. Estos autores usan dos concentraciones críticas de $\mathrm{P}$ en la solución del suelo $\left(0,02 \mathrm{mg} \cdot \mathrm{L}^{-1}\right.$ y 0,2 mg. $\mathrm{L}^{-1}$ para clasificar las especies vegetales así:

- Independiente: especies que no son colonizadas por hongos formadores de micorrizas y que no responden positivamente a la infección micorrizal arbuscular.

- Marginal: especies con una DM de menos del 25\% a una concentración de P en la solución del suelo de 0,02 mg. $\mathrm{L}^{-1}$.

- Moderada: especies con una DM de 25-50\% a una concentración de P en la solución del suelo de $0,02 \mathrm{mg} \cdot \mathrm{L}^{-1}$.

- Alta: especies con una DM de 50 - 75\% a una concentración de P en la solución del suelo de 0,02 mg. $\mathrm{L}^{-1}$ y no responden significativamente a la inoculación a 0,2 mg. $\mathrm{L}^{-1}$. 
- Muy alta: especies con una $\mathrm{DM} \geq 75 \%$ a una concentración de $\mathrm{P}$ en la solución del suelo de 0,02 mg. $\mathrm{L}^{-1}$ y responden significativamente a la inoculación a 0,2 mg. $\mathrm{L}^{-1}$.

Es evidente que existen diferencias en la dependencia de las plantas por la asociación micorrizo-arbuscular. Entre las altamente dependientes se tienen leucaena, yuca, café, mientras que otras son completamente independientes de tal asociación, como repollo. Además, también se han reportado diferencias en la DM entre cultivares de una misma especie. Este tipo de investigaciones se han llevado a cabo en Allium fistulosum, Lycopersicon esculentum Mill., Zea mays L., Glycine soja y Glycine max, Hordeum vulgare L. y Glycine max y Solanum aethiopicum.

La DM de algunas especies vegetales de interés económico agrícola y forestal ha sido determinada recientemente (Tabla 8, Figura 4). En general, la DM varía en función del nivel de $\mathrm{P}$ disponible en el suelo. Se ha detectado que a concentraciones muy bajas de $\mathrm{P}$ en la solución del suelo $\left(\sim 0,002 \mathrm{mg} \cdot \mathrm{L}^{-1}\right)$ la inoculación micorrizal no aumenta el crecimiento de las plantas. La mejor respuesta a la inoculación micorrizal, en biomasa y absorción de $\mathrm{P}$, se obtiene con una concentración de $\mathrm{P}$ soluble de 0,02 mg. $\mathrm{L}^{-1}$. A concentraciones muy altas de $\mathrm{P}\left(\sim 0,2 \mathrm{mg} \cdot \mathrm{L}^{-1}\right)$ la respuesta de algunas plantas a la inoculación micorrizal ha sido variable, en algunos casos el crecimiento ha disminuido y, por ende, el valor de DM es negativo.

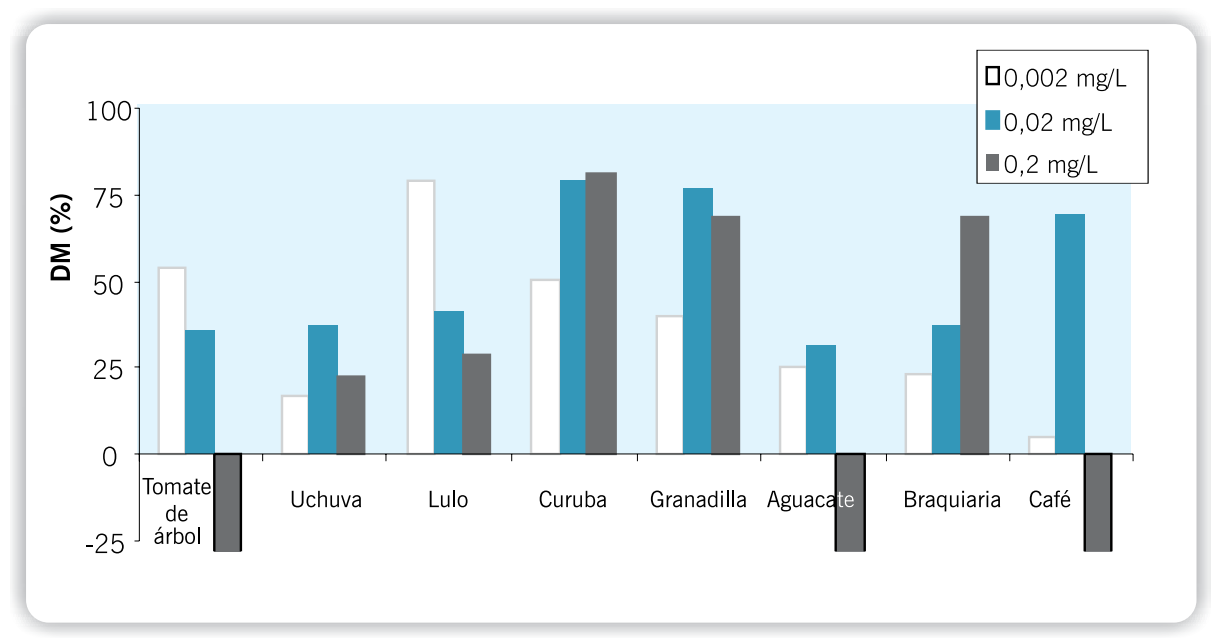

Figura 4. Dependencia micorrizal (DM) de algunas especies vegetales tropicales de interés económico. Fuente: Osorio, no publicado.

\section{Inoculación micorrizal}

La inoculación hace referencia al proceso de aplicar alrededor del sistema radical de la planta, un sustrato que contenga estructuras infectivas (esporas, hifas, raíces infectadas), con el fin de lograr la colonización de las raíces. La inoculación micorrizal se facilita en 
Tabla 8. Categorías de dependencia micorrizal (DM) de algunas especies vegetales de interés económico.

\begin{tabular}{|c|c|c|}
\hline $\begin{array}{l}\text { Categoría } \\
\text { DM }\end{array}$ & Especie vegetal & Referencia \\
\hline \multirow[b]{2}{*}{ Independiente } & Brassica nigra & $\begin{array}{l}\text { Habte y Manjunath, } \\
1991\end{array}$ \\
\hline & $\begin{array}{l}\text { Platyciamus regnellii Benth., Ormosia aborea (Vell.), } \\
\text { Platypodium elegans Vog., Macheria stipitatum (DC), } \\
\text { Myroxylon peruiferum L.f., Hymenaea courbaril L., } \\
\text { Dendropanax cuneatum (DC), Ceiba speciosa (St.Hil), } \\
\text { Tabebuia roseo-alba (Rid.). }\end{array}$ & $\begin{array}{l}\text { Siqueira y Saggin } \\
\text { Junior, } 2001\end{array}$ \\
\hline Marginal & $\begin{array}{l}\text { Sesbania formosa, S. pachycarpa, S. sesban } \\
\text { Cassia reticulata Willd, Chloris gayana Kunth. } \\
\text { Hordeum vulgare L. cv. Vodka }\end{array}$ & $\begin{array}{l}\text { Habte y Manjunath, } \\
1991 \\
\text { Habte, no publicado } \\
\text { Plenchette y Morel, } \\
1996\end{array}$ \\
\hline \multirow{3}{*}{ Moderada } & $\begin{array}{l}\text { Acacia mangium Willd., Colocasia esculenta (L.), } \\
\text { Gliricidia sepium (Jacq.) }\end{array}$ & Habte, no publicado \\
\hline & Leucaena retusa, Sesbania grandiflora & $\begin{array}{l}\text { Habte y Manjunath, } \\
1991\end{array}$ \\
\hline & Acacia koa & Miyasaka et al., 1993 \\
\hline \multirow{5}{*}{ Alta } & $\begin{array}{l}\text { Manihot esculanta Crantz } \\
\text { Sophora crhysophylla }\end{array}$ & $\begin{array}{l}\text { Habte y } \\
\text { Byappanahalli, } 1994 \\
\text { Miyasaka et al., } 1993\end{array}$ \\
\hline & Cassia siamea & Habte, 1995 \\
\hline & Leucaena diversifolia, Leucaena trichodes & $\begin{array}{l}\text { Habte y Manjunath, } \\
1991\end{array}$ \\
\hline & $\begin{array}{l}\text { Sesbania tormentosa } \\
\text { Albizia ferruginea, Allium cepa L., Azadirachta indica A. } \\
\text { Juss, } \\
\text { Cajanus cajan, Enterolobium cyclocarpum Jcq., } \\
\text { Paraserianthes falcataria (L.), Sauropus androgynus (L.) }\end{array}$ & $\begin{array}{l}\text { Gemma et al., } 2002 \\
\text { Habte, no publicado }\end{array}$ \\
\hline & $\begin{array}{l}\text { Aspidosperma parvifolium A.DC., Solanum granuloso } \\
\text { leprosum,Lithraea molleoides (Vell.), Trema micranta (L.) }\end{array}$ & $\begin{array}{l}\text { Siqueira y } \\
\text { SagginJunior, } 2001\end{array}$ \\
\hline \multirow[t]{3}{*}{ Muy alta } & $\begin{array}{l}\text { Luehea grandiflora Mart., Senna spectabilis (A.DC.), } \\
\text { Croton floribundus Spreng, Tibouchina granulosa Cogn., } \\
\text { Cecropia pachystachya Trec., Cordia trichotoma (Vell.), } \\
\text { Senna macranthera (Collad), Cedrella fissilis Vell., } \\
\text { Caesalpinia ferrea Mart., Myrsine umbellata Mart., } \\
\text { Tabebuia impetiginosa (Mart.), Sapindus saponaria L., } \\
\text { Tabebuia serratifolia (Vahl), Copaifera lagsdorffii Desf. }\end{array}$ & $\begin{array}{l}\text { Siqueira y Saggin- } \\
\text { Junior, } 2001\end{array}$ \\
\hline & Leucaena leucocephala & $\begin{array}{l}\text { Habte y Manjunath, } \\
1991\end{array}$ \\
\hline & $\begin{array}{l}\text { Bidens sandvicencis } \\
\text { Glycine max L. cv. Maple arrow }\end{array}$ & $\begin{array}{l}\text { Gemma et al., } 2002 \\
\text { Plenchette y Morel, } \\
1996\end{array}$ \\
\hline
\end{tabular}


aquellos cultivos que tienen una fase de semillero, vivero o almácigo (Figura 5). En esos casos se puede aplicar el inóculo en el hoyo donde se siembra la semilla o la plántula. También se puede mezclar el inóculo con el sustrato de crecimiento de las raíces. La dosis es variable (20-40 $\mathrm{g} \mathrm{kg}^{-1}$ de suelo) y depende, en buena parte, de la calidad del inóculo.

Antes de inocular un suelo es necesario conocer el grado de dependencia micorrizal de la especie vegetal que se requiere cultivar. Se recomienda la aplicación de inóculo micorrizal cuando:

- Las plantas requieren altas cantidades de $P$

- La concentración de P disponible es baja

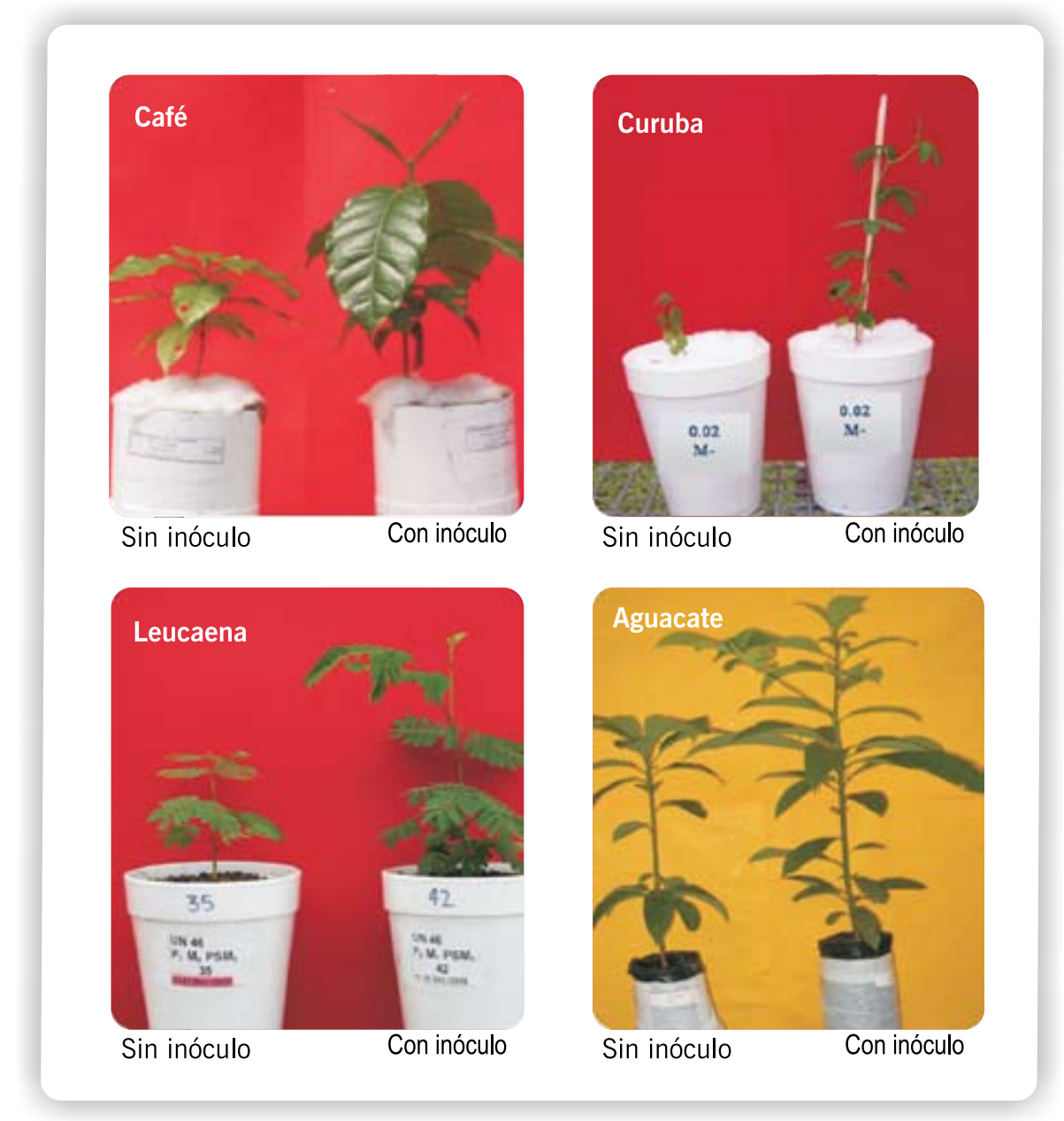

Figura 5. Efecto de la inoculación micorrizal sobre el crecimiento de plántulas de café, curuba, leucaena y aguacate. En todos los casos la concentración de P en la solución del suelo fue de 0,02 mg. L-1 . Fuentes: Jaramillo (2006), Corredor (2007), Montoya (2007), Osorio (2008). 
- La población de AMF nativa del suelo es escasa, poco agresiva e ineficaz. Como ocurre en suelos erosionados, degradados o contaminados

- Se ha realizado un manejo intensivo de fungicidas

- La especie vegetal depende de la asociación micorrizal

\section{Fertilización fosfórica y AMF}

En muchos sistemas agrícolas la recuperación del $\mathrm{P}$ aplicado por parte de las plantas es muy baja porque más del 80 al 90\% del P aplicado no queda disponible en la solución del suelo, particularmente en suelos de la zona tropical y subtropical. El P aplicado puede ser fuertemente fijado en el suelo. El término "fijación de P" es usado en referencia a una serie de reacciones que remueven el $\mathrm{P}$ disponible de la solución del suelo, de donde las raíces lo toman directamente. El $\mathrm{P}$ puede ser adsorbido fuertemente por minerales arcillosos del suelo y óxidos e hidróxidos de Fe y Al. Además, el P se puede precipitar al formar compuestos insolubles con iones de Al, Fe y Ca. Sánchez y Logan (1992) estimaron que 1.018 millones de hectáreas en el trópico tienen una alta capacidad de fijación de P. En América tropical hay 659 millones de hectáreas afectadas, 210 en África y 199 en Asia.

Consecuentemente, el P se mueve lentamente hacia la solución del suelo por difusión y la alta rata de captación por parte de la planta crea una zona de agotamiento alrededor de la raíz, dificultándose así su absorción. Por lo tanto, la tarea de captar este nutriente recae en las hifas de los AMF.

Pese a los efectos benéficos de la aplicación de fertilizantes fosfóricos $P$ en los sistemas de producción agrícola modernos, éste puede llegar a ser un contaminante si logra pasar por escorrentía desde los suelos agrícolas hasta los cuerpos de agua sensibles a eutrofización. El movimiento de P soluble en la superficie del suelo y su transporte asociado a partículas de suelo y material vegetal erosionado puede llegar a aguas donde sea biodisponible para la biota acuática. Un aspecto clave es mejorar la eficiencia en el uso de P del suelo. Ya que los AMF aumentan la captación de P por las plantas, se ha sugerido que estos microorganismos pueden reducir los requerimientos de fertilizantes fosfatados. Tal reducción puede disminuir, al menos en parte, los riesgos de eutrofización en los ecosistemas acuáticos que rodean los suelos agrícolas.

\section{MICROORGANISMOS SOLUBILIZADORES DE FÓSFORO (PSM)}

En años recientes, los microorganismos solubilizadores de P (PSM, por sus siglas en inglés) de la rizosfera han recibido mucha atención. La mayoría de las bacterias del suelo pueden solubilizar fosfatos insolubles, pero son particularmente activas, aquellas que pertenecen a los géneros Pseudomonas, Enterobacter y Bacillus. Así mismo, son particularmente activos como PSM los hongos de los géneros Penicillium y Aspergillus. Algunos investigadores prefieren usar hongos solubilizadores de $P$, argumentando que las bacterias pueden perder su habilidad para solubilizar $\mathrm{P}$ después de varios ciclos de cultivo in vitro, pero este punto es bastante controversial. 
La razón para estudiar estos microorganismos es que uno de los problemas más importantes en agricultura tropical es la baja disponibilidad de $\mathrm{P}$ en el suelo, como se mencionó anteriormente. Muchos de los suelos tropicales son altamente meteorizados y tienen una alta capacidad de fijación de P, que hace más difícil su manejo. En décadas pasadas se han empleado varias estrategias para reducir la fijación de P, éstas consisten en usar altas dosis de fertilizantes fosfóricos solubles. Sin embargo, la eficiencia de los fertilizantes fosfóricos es baja (5-10\%) debido a la alta fijación en los suelos. Una opción viable es el uso de las rocas fosfóricas (RP; apatita), sin embargo, estos materiales son muy insolubles, particularmente en suelos neutros y alcalinos, y siempre se desea un poco más de reactividad.

En las décadas de 1950 y 1960, la inoculación con Bacillus megatherium var. phosphaticum (fosfobacterin) en suelos de Rusia (principalmente Mollisoles), ha sido la mejor referencia conocida del uso masivo de PSM. Las pruebas que se realizaron en diferentes lugares, mostraron la poca consistencia en la respuesta de las plantas con la inoculación del fosfobacterin. Aparentemente, otros factores tales como el encalamiento y el contenido de materia orgánica del suelo afectaban la efectividad del fosfobacterin para incrementar el P disponible del suelo. El uso del fosfobacterin se desestímulo debido a: (i) la falta de respuesta en el rendimiento de los cultivos evaluados en muchos lugares; (ii) la preocupación de que el fosfobacterin aceleraría la descomposición de la materia orgánica del suelo y (iii) el pobre conocimiento de los mecanismos de solubilización de P en ese entonces. Desde entonces, la investigación sobre la solubilización microbial de fosfatos fue orientada a estudiar la disolución de fosfatos inorgánicos.

Un inóculo comercial de un PSM (Penicillium bilaii) Ilamado Provide ${ }^{\mathrm{TM}}$ es comercialmente disponible en Norte América y ha sido satisfactoriamente probado en varias plantas para incrementar la absorción de P por la planta. La eficiencia de PSM ha sido cuestionada por algunos autores porque: (i) las sustancias orgánicas requeridas por estos microorganismos son escasas en sitios no-rizosféricos, (ii) existe antagonismo y competencia con otros microorganismos en la rizosfera y (iii) hay baja translocación de fosfatos solubilizados a través del suelo, ya que éstos pueden ser otra vez fijados por componentes del suelo.

\section{Mecanismos de la solubilización microbial de fósforo en la rizosfera}

A pesar de las dudas sobre la efectividad de los PSM se han encontrado respuestas positivas sobre el crecimiento vegetal y la absorción de $\mathrm{P}$ al inocular el suelo con PSM. Los principales mecanismos involucrados en la solubilización microbial de $\mathrm{P}$ son la producción de ácidos orgánicos y la liberación de protones a la solución del suelo. Los ácidos comúnmente reportados por los investigadores de PSM son ácido glucónico, ácido oxálico, ácido cítrico, ácido láctico, ácido tartárico y ácido aspártico. Estos ácidos son el producto del metabolismo microbiano, principalmente por respiración oxidativa o por fermentación de carbono orgánico soluble, por ejemplo la glucosa. La producción de ácidos orgánicos por los PSM se incrementa si la fuente de $\mathrm{N}$ es amonio en lugar de nitrato.

Cuando el suelo es inoculado con PSM, los ácidos orgánicos disminuyen el pH de la rizosfera y favorece así la solubilización de las rocas fosfóricas. Considere la siguiente reacción de un fosfato dicálcico del suelo y una hidroxiapatita (RP aplicada): 


$$
\begin{gathered}
\text { (Fosfato dicálcico) } \mathrm{CaHPO}_{4}+\mathrm{H}^{+} \leftrightarrow \mathrm{H}_{2} \mathrm{PO}_{4}{ }^{-}+\mathrm{Ca}^{2+} \\
\text { (Hidroxiapatita) } \mathrm{Ca}_{5}\left(\mathrm{PO}_{4}\right)_{3}(\mathrm{OH})+4 \mathrm{H}^{+} \leftrightarrow 3 \mathrm{HPO}_{4}{ }^{2-}+5 \mathrm{Ca}^{2+}+\mathrm{H}_{2} \mathrm{O}
\end{gathered}
$$

Si la actividad de $\mathrm{H}^{+}$incrementa, las reacciones ocurren hacia la derecha, tal como están escritas. Por otro lado, la presencia de ácidos/aniones orgánicos reduce la actividad de $\mathrm{Ca}^{2+}$ en los productos de tales reacciones al formar complejos estables con este ión. De esta forma se favorece aún más la liberación del P.

Recientemente, se ha detectado la liberación de ácido oxálico por un hongo solubilizador de $\mathrm{P}$ (Mortierella sp.) que puede desabsorber el $\mathrm{P}$ que se encuentra sobre minerales arcillosos. La capacidad para desabsorber $\mathrm{P}$ está controlada por el tipo de suelo y de mineral arcilloso dominante en el suelo. En este sentido, la desorción de P inducida por el hongo ha sido más efectiva, en el siguiente orden:

$$
\text { Mollisol > Oxisol > Ultisol > Andisol }
$$

Consecuentemente, se ha detectado que la efectividad en la desorción de P es como sigue:

$$
\text { Montmorillonita }>\text { Caolinita }>\text { Gibsita }>\text { Alofana }
$$

\section{Interacciones PSM y AMF}

Al inocular el suelo conjuntamente con AMF y PSM se puede mejorar la efectividad en la absorción de P solubilizado. Las plantas micorrizadas pueden liberar una mayor cantidad de sustancias carbonadas en su rizosfera (micorrizosfera) que las plantas no micorrizadas, y los PSM ubicados en la la rizosfera (o micorrizosfera) liberarían más ácidos orgánicos a la solución del suelo para disolver fosfatos insolubles (P-Ca). Por otro lado, las hifas extrarradicales podrían captar más eficientemente el fosfato liberado por los PSM en la rizosfera (Figura 6), evitando así la fijación.

Kim et al. (1998) estudiaron el efecto de la inoculación individual y dual de Enterobacter agg/omerans (PSM) y Glomus etunicatum (AMF) sobre el crecimiento del tomate y la captación de P. Estos autores encontraron un efecto sinérgico sobre el desempeño vegetal cuando ambos microorganismos fueron inoculados en un Alfisol fertilizado con roca fosfórica (Tabla 9). El efecto se debió a una mayor producción de ácido oxálico y, en consecuencia, la roca fosfórica se disolvió y produjo una mayor concentración de P en la rizosfera. En este experimento fue aplicada glucosa como fuente de energía para incrementar la liberación de ácidos orgánicos por el PSM. Resultados similares observaron Osorio y Habte (2001) en leucaena, al inocular un Oxisol de Hawai fertilizado con RP con el AMF Glomus aggregatum y el PSM Mortierella sp. (Tabla 10). La respuesta a la inoculación con ambos depende del tipo de suelo y particularmente de la capacidad del suelo para fijar P (Figura 7). Osorio (2008) encontró que en un Mollisol (con baja capacidad para fijar P) el PSM fue tan efectivo como el AMF para incrementar el crecimiento de leucaena. En el Oxisol (moderada capacidad para fijar P) el AMF fue efectivo y el PSM inefectivo para mejorar el desempeño de la leucaena, el efecto fue mayor con ambos. En el Andisol (muy alta fijación de P) ni las inoculaciones individuales ni la combinación fueron efectivas. 


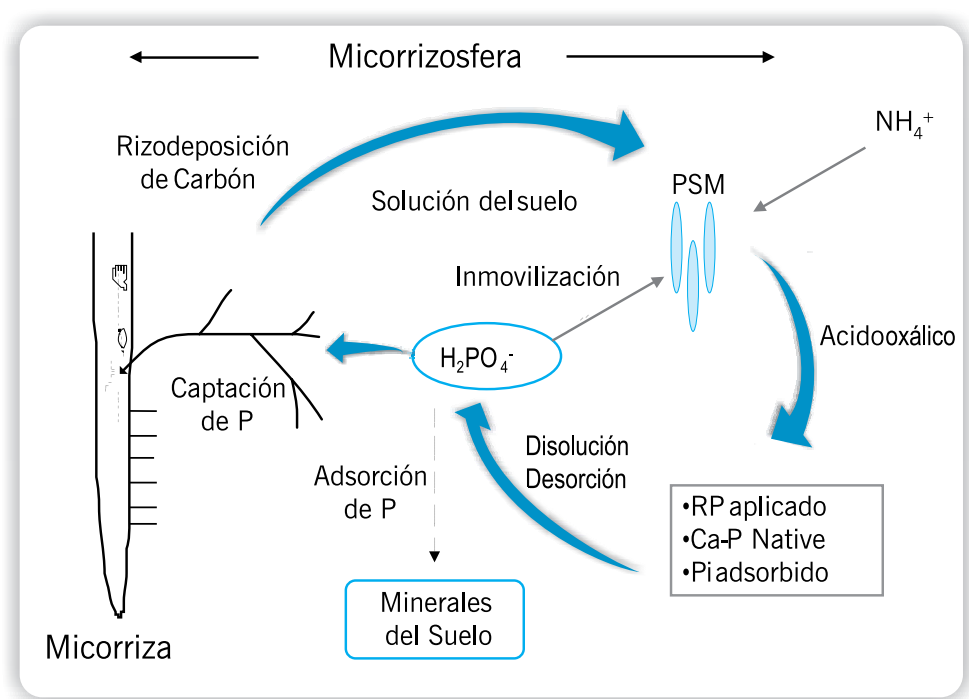

Figura 6. Solubilización microbial de fosfatos en la micorrizosfera y captación micorrizal de P (dibujo original de N.W. Osorio).

Tabla 9. Efectos de la inoculación de E. agg/omerans (PSM) y G. etunicatum (AMF) en el crecimiento y absorción de $\mathrm{P}$ en plantas de tomate (75 días después de la inoculación). Fuente: Kim et al. (1998).

\begin{tabular}{lcccc} 
& Masa seca de & Masa seca & \multicolumn{2}{c}{ P total } \\
\cline { 4 - 5 } Tratamientos & $\begin{array}{c}\text { Marte aérea } \\
\text { (g/planta) }\end{array}$ & $\begin{array}{c}\text { de las raíces } \\
\text { (g/planta) }\end{array}$ & $\begin{array}{c}\text { Parte aérea } \\
\text { (g/planta) }\end{array}$ & $\begin{array}{c}\text { Raíces } \\
\text { (g/planta) }\end{array}$ \\
\hline Control & 42,2 & 4,29 & 116,46 & 11,9 \\
PSM & 48,49 & 5,10 & 125,26 & 13,6 \\
AMF & 47,62 & 5,57 & 120,94 & 13,4 \\
PSM + AMF & 54,56 & 6,77 & 134,41 & 16,7 \\
LSD $(\mathrm{P}<0,05)$ & 1,96 & 0,53 & 9,85 & $\mathrm{NS}$ \\
\hline
\end{tabular}

Tabla 10. Efecto de la inoculación con G. fasciculatum (AMF) y Mortierella sp. (PSM) sobre el crecimiento (g/pote) de leucaena en tres suelos tropicales de Colombia. Adaptado de Osorio (2008). Comparación vertical (Prueba de LSD, $P \leq 0,05$ ).

\begin{tabular}{|c|c|c|c|}
\hline Tratamiento & $\begin{array}{c}\text { Mollisol } \\
\left(P_{0,2}=45 \text { mg.kg-1 }\right)\end{array}$ & $\begin{array}{c}\text { Oxisol } \\
\left(P_{0,2}=417 \mathrm{mg} \cdot \mathrm{kg}^{-1}\right)\end{array}$ & $\begin{aligned} & \text { Andisol } \\
\left(P_{0,2}=\right. & \left.2.222 \mathrm{mg} \cdot \mathrm{kg}^{-1}\right)\end{aligned}$ \\
\hline PSM & 1,18 & 0,30 & 0,28 \\
\hline AMF & 1,36 & 0,84 & 0,28 \\
\hline PSM+AMF & 1,48 & 0,97 & 0,26 \\
\hline LSD & 0,09 & 0,12 & 0,09 \\
\hline
\end{tabular}




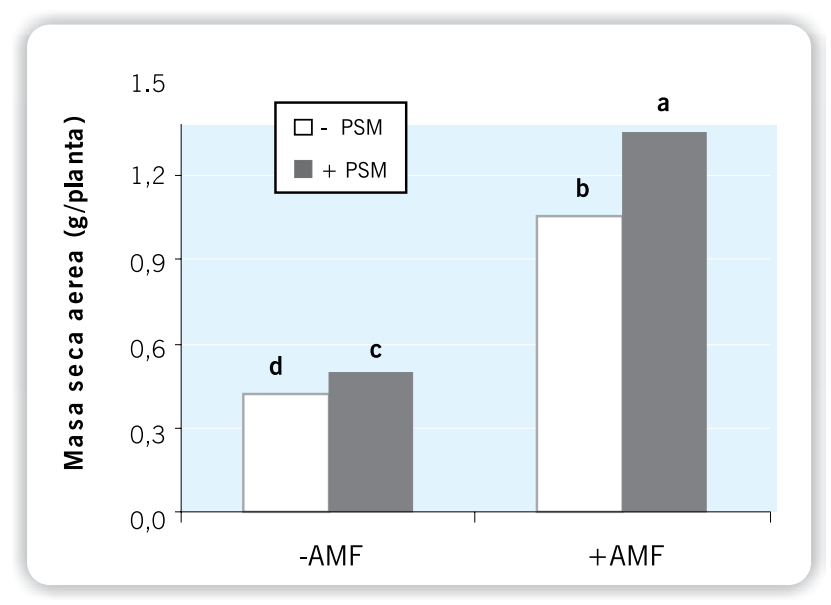

Figura 7. Efecto de la inoculación con $G$. aggregatum (HMA) y Mortierella sp. (PSM) sobre la masa seca aérea de Leucaena leucocephala. Fuente: Osorio y Habte (2001).

Efectos sinérgicos han sido reportados en girasol (Helianhus annuus) con la inoculación triple de Azobacter chroococcum, Penicillium glaucum y Glomus fasciculatum; en pimentón (Capsicum annuum) con G. fasciculatum o G. macrocarpum y P. striata; en trigo con $P$. putida, $P$. aeruginosa y $P$. fluorescens en combinación con G. clarum. Así mismo, P. striata y $G$. fasciculatum. En trigo también se han obtenido resultados positivos con la combinación de dos PSM, P. striata y Agrobacterium radiobacter, con G. fasciculatum y Gigaspora margarita, el mayor crecimiento de la planta se obtuvo cuando fueron adicionados estos microorganismos y fertilizantes.

Kopler et al. (1988) encontraron más nodulación de rizobios sobre la raíz de una leguminosa al inocular también con el PSM Pseudomonas spp. Sturz et al. (1997) encontraron que la nodulación de Rhizobium leguminosarum b.v. trifolii fue promovida en trébol rojo (Trifolium pratense) cuando éste fue co-inoculado con Bacillus insolitus, $B$. brevis o Agrobacterium rhizogenes. Resultados similares se obtuvieron con la inoculación de G. mosseae y Azorhizobium caulinodans en Sesbania rostrata. En soya la combinación de Bradyrhizobium japonicum, P. fluorescens y G. mosseae ha dado igualmente buenos resultados, debido probablemente a una mayor captación de P, promovida por los PSM y AMF, lo cual puede satisfacer los altos requerimientos de $P$ del proceso de fijación simbiótica de $\mathrm{N}_{2}$.

Los PSM también han sido probados en la industria de fertilizantes fosfóricos. Usualmente la roca fosfórica es parcialmente acidulada con ácidos inorgánicos (p.e., $\mathrm{H}_{2} \mathrm{SO}_{4}$ ) para incrementar su reactividad, o usada como materia prima para producir más fertilizantes solubles, para lo cual también son adicionados algunos ácidos fuertes. Esto es un proceso costoso debido a los altos costos de los ácidos inorgánicos. Bar-Yosef et al. (1999) encontraron que la bacteria Pseudomonas cepacia, un conocido PSM, fue muy eficiente para oxidar glucosa y producir ácido glucónico y ácido 2-ketoglucónico en un reactor que contiene RP. Una vez los ácidos fueron disociados, los protones reaccionaron con la RP y liberaron iones fosfato que fueron precipitados con $\mathrm{Ca}^{2+}$ para formar fertilizantes solubles (superfosfatos). Así, la actividad de los PSM no sólo genera beneficio en su nicho natural, la rizosfera, sino también en otros ambientes. 
Los microorganismos del suelo representan una parte integral del suelo. Sus funciones son vitales para la disponibilidad de nutrientes del suelo (fertilidad del suelo). Estos microorganismos determinan la dinámica de la descomposición de la materia orgánica y por consiguiente, liberan nutrientes de ésta a la solución del suelo. Además, participan en diferentes reacciones que incrementan la disponibilidad de nutrientes o su absorción por las raíces. También, los microorganismos del suelo pueden facilitar la pérdida de algunos elementos del suelo (p.e., denitrificación). El conocimiento de tales interacciones puede permitirnos intervenir en el manejo del suelo para maximizar los beneficios de la actividad microbiana del suelo.

\section{Literatura citada}

Arines J, Porto ME, Vilarino A (1992). Effect of manganese on vesicular-arbuscular mycorrhizal development in red clover plant and soil Mn-oxidizing bacteria. Mycorrhiza 1:127-131.

Asea PEA, Kucey RMN, Stewart JWB (1988). Inorganic phosphate solubilisation by 2 Penicillium species in solution culture and soil. Soil biology and Biochemistry 20:459-464.

Atlas R, Bartha R (1997). Microbial Ecology. Addison Wesley Longman, New York.

Azam F, Memom GH (1996). Soil organisms. In: Bashir E and Bantel R (ed.) Soil science. National Book Foundation, Islamabad, 200-232 p.

Azcon C, Barea JM (1996). Interactions of arbuscular mycorrhiza with rhizosphere microorganisms. In: Guerrero E (ed.) Mycorrhiza: Biological soil resource. FEN, Bogotá, Colombia, 47-68 pp.

Barber SA (1995). Soil nutrient biovalability. A mechanistic approach. John Wiley and Sons, New York.

Bar-Yosef B, Rogers RD, Wolfram JH, Richman E (1999). Pseudomonas cepacia-mediated rock phosphate solubilization in kaolinite and montmorillonite suspensions. Soil Science Society of America Journal 63:1703-1708.

Bashan Y, Holguin G (1998). Proposal for the division of Plant Growth Promoting Rhizobacteria into two classifications: Biocontrol-PGPB and PGPB. Soil Biology and Biochemistry 30:1225-1228.

Bashan Y, Rojas A, Puente ME (1999). Improved establishment and development of three cactus species inoculated with Azospirillum brasilense transplanted into disturbed urban desert soils. Canadian Journal of Microbiology 45:441-451.

Bass R (1990). Effects of Glomus fasciculatum and isolated rhizosphere microorganisms on growth and phosphate uptake of Plantago major spp. pleiosperma. Plant and Soil 124:187-193.

Bolan NS (1991). A critical review on the role of mycorrhizal fungi in the uptake of phosphorus by plants. Plant and Soil 134:189-207.

Bolan NS, Naidu R, Mahimairaja S, Baskaran S (1994). Influence of low-molecular-weight organic acids on the solubilization of phosphates. Biology and Fertility of Soils 18:311-319.

Burleigh SH, Harrison MJ (1999). The down-regulation of Mt4-Like genes by phosphate fertilization occurs systemically and involves phosphate translocation to the shoots. Plant Physiology 119: 241-248. 
Bowen GD, Rovira AD (1999). The rhizosphere and its management to improve plant growth. Advances in Agronomy 66:1-102.

Carillo-García A, Bashan Y, Diaz E, Bethlenfalvay GJ (2000). Effects of resource-island soils, competition, and inoculation with Azospirillium on survival and growth of Pachycereus pringlei, the giant cactus of the Sonoran desert. Restoration Ecology 8 (1):65-73.

Chanway CP (1997). Inoculation of tree roots with plant promoting soil bacteria: an emerging technology for reforestation. Forest Science 43 (1):99-112.

Corredor A (2007). Dependencia micorrizal de curuba y granadilla. Tesis de grado Biología, U de A, Medellín.

De la Fuente JM, Herrera L (1999). Advances in the understanding of aluminum toxicity and the development of aluminum tolerant transgenic plants. Advances in Agronomy 66:103-121.

Dinkelaker B, Romheld V, Marschner H (1989). Citric acid excretion and precipitation of calcium citrate in the rhizospher of white lupin (Lupinus albus). Plant Cell Environment 12:285-292.

Engelstad OP, Terman GL (1980). Agronomic effectiveness of phosphate fertilizers. In: Khasawneh FE, Sample E, Kamprath E (ed.) The role of phosphorus in agriculture. Soil Science Society of America, Madison, WI, 311-332 pp.

Foth HD, Ellis BG (1996). Soil fertility. Lewis Publishers, Boca Raton, FL.

Frankenberg WT, Arshad M (1995). Phytohormones in soils: microbial production and function. Dekker, New York.

Freitas JR, Banerjee MR, Germida JJ (1997). Phosphate solubilizing rhizobacteria enhance the growth and yield but not phosphorus uptake of canola (Brassica napus L.). Biology and Fertility of Soils 24:358-364.

Germida JJ, Walley FL (1996). Plant growth-promoting rhizobacteria alter rooting patterns and arbuscular mycorrhizal fungi colonization of fiels-grown spring wheat. Biology and Fertility of Soils 23: 113-120.

Graham PH (1999). Biological dinitrogen fixation: symbiotic. In: Sylvia D, Fuhrmann J, Hartel P, Zuberer D (ed.) Principles and Applications of Soil Microbiology. Prentice Hall, Upper Saddle River, NJ, 322-368 pp.

Graham RD, Webb MJ (1991). Micronutrients and plant disease resistance and tolerance in plants. In: Morvedt J, Cox FR, Shuman LM, Welch RM (ed.) Micronutrients in Agriculture. Soil Science Society of America, Madison, WI, (Books series No.4), 329-370 pp.

Gray TRG, Williams ST (1971). Microbial productivity in soil. In: Hughes D, Rose AH (eds) Microbes and microbial productivity, $21^{\text {st }}$ Symp. Soc. Gen. Microbiol. Cambridge Univ. Press, London 255-286 pp.

Habte M, Manjunath A (1991). Categories of vesicular-arbuscular dependency of host species. Mycorrhiza 1:3-12.

Hammond L, Leon L (1992). Evaluation of the North Caroline natural phosphate as a phosphoric fertilizer. Suelos Ecuatoriales 22:143-150. 
Havlin J, Beaton J, Tisdale SL, Nelson W (1999). Soil Fertility and Fertilizers. Prentice Hall, Upper Saddle River, NJ.

He ZL, Zhu J (1998). Microbial utilization and transformation of phosphate adsorbed by variable charge minerals. Soil Biology and Biochemistry 30:917-923.

Hiltner L (1904). Uber neure Erfahrungen und probleme auf dem gebiet der bockenbakteriologie und unter besonderer bercksichtigung der grundungung un brache. Arb. Dtsch. Landwirt. Ges 98:5978.

Hue NV, Silva J, Uehara G, Hamasaki RT, Uchida R, Bunn P (1998). Managing manganese toxicity in former sugarcane soils of Oahu. Honolulu, Cooperative Extension Service, University of Hawai'i.

Hue NV, Vega S, Silva J (2001). Manganese toxicity in a Hawai'i an Oxisol affected by soil pH and organic amendments. Soil Science Society of America Journal 65:153-160.

Hue NV (1991). Effects of organic acids/anions on P sorption and phytoavailability in soils with different mineralogies. Soil Science 152:463-471.

Ingham E (1999). Protozoa and nematodes. In: Sylva D, Furhmann JF, Harte PG, Zuberer DA (eds) Principles and applications of soil microbiology. Prentice Hall, New Jersey, 114-131 pp.

Jaramillo S (2006). Dependencia micorrizal del cafeto cv. Colombia y Caturra. 2006. Tesis de Maestría en Biotecnología, Universidad Nacional de Colombia, Medellín.

Kenedy A (1999). The rhizosphere and spermosphere. In: Sylvia D, Fuhrmann J, Hartel P, Zuberer D (eds) Principles and Applications of Soil Microbiology. Prentice Hall, Upper Saddle River, NJ, 389$407 \mathrm{pp}$.

Kim KY, McDonald GA, Jordan D (1997). Solubilization of hydroxyapatite by Enterobacter agglomerans and cloned Escherichia coli in culture medium. Biology and Fertility of Soils 24:347-352.

Kim KY, Jordan D, McDonald GA (1998). Effect of phosphate solubilizing bacteria and vesiculararbuscular mycorrhizae on tomato growth and soil microbial activity. Biology and Fertility of Soils 26:79-87.

Kopler J, Lifshitz R, Schroth M (1988). Pseudomonas inoculants to benefit plant production. Isi atlas of science, animal and plant sciences 1:60-64.

Kucey RMN (1983). Phosphate solubilising bacteria and fungi in various cultivated and virgin Alberta soils. Canadian Journal of Soil Science 63:671-678.

Kuenen JG, Robertson LA (1994). Combined nitrification-denitrification processes. FEMS Microbiological Reviews 15:109-117.

Lazarovitz G, Nowak J (1997). Rhizobacteria for improvement of plant growth and establishment. Hort Science 32:188-192.

Linderman RG (1988). Mycorrhizal interaction with the rhizosphere microflora: The mycorhizosphere effect. Phytopathology 78:366-371.

Lindsay W (1979). Chemical equilibria in soils. John Wiley and Sons, New York. 
Marschner H (1995). Mineral Nutrition of Higher Plants. London, Academic Press.

Marschner H, Dell B (1994). Nutrient uptake in mycorrhizal symbiosis. In: Robson AD, Abott LK, Malaccjuk N (eds) Management of mycorrhizas in agriculture, horticulture and forestry. Academic publishers, the Netherlands, 89-102 pp.

McCully M (1999). Roots in soil: unearthing the complexities of roots and their rhizospheres. Annual Review of Plant Physiology and Plant Molecular Biology 50:695-718.

Meeting FB (1993). Structure a physiological ecology of soil microorganisms. In: Meeting FB (ed.) Soil microbial ecology: applications in agricultural and environmental management. Marcel Dekker, New York, 3-25 pp.

Mohod S, Gupta DN, Chavan AS (1991). Effects of P solubilizing organims on yield and N uptake by rice. Journal of Maharashtra agricultural universities 16 (2):229-231.

Montoya B (2007). Dependencia micorrizal del aguacate. Tesis de Maestría en Geomorfología y Suelos, Universidad Nacional de Colombia, Medellín.

Mullen MD (1999). Transformations of other elements. In: Sylva D, Furhmann JF, Harte PG, Zuberer DA (eds) Principles and applications of soil microbiology. Prentice Hall, New Jersey, 369- 386 pp.

OkonY (1994). Azospirillium plant associations. CRC Press, Boca Raton, FI.

Osorio, N.W. (2002). Aislamiento y evaluación de microorganismos solubilizadores de fósforo en suelos de Hawaii. Universidad Nacional de Colombia, Medellín.

Osorio NW (2008). Effectiveness of microbial solubilization of phosphate in enhancing plant phosphate uptake in tropical soils and assessment of the mechanisms of solubilization. Ph. Dissertation, University of Hawai'i, Honolulu.

Osorio NW, Habte M (2001). Synergistic influence of an arbuscular mycorrhizal fungus and $P$ solubilizing fungus on growth and plant $\mathrm{P}$ uptake of Leucaena leucocephala in an Oxisol. Arid Land Research and Management. 15:263-274.

Papavizas GC, Davey CB (1961). Extent and nature of the rhizosphere of Lupinus. Plant and Soil 14:215-236.

Patgiri I, Bezbaruah B (1990). Strains contributing to phosphorus mobilization in acid soils. Indian Journal of Agricultural Sciences 60 (3):197-200.

Paul EA, Clark FE (1989). Soil microbiology and biochemistry. Academic Press, New York, 49-73 pp.

Plenchette C, Fortin J A, Furlan V (1983). Growth response of several plant species to mycorrhiza in a soil of moderate $P$ fertility. Plant Soil 70:199-209.

Prathibha CK, Alagawadi A, Sreenivasa M (1995). Establishment of inoculated organisms in rhizosphere and their influence on nutrient uptake and yield cotton. Journal of Agricultural Sciences 8(1):22-27.

Premono E, Anas I, Soepardi G, Hadioetomo R, Saono S, Sisworo W (1994). Isolation and selection of phosphate-solubilizing microorganims from a sugarcane plantation. Majalah Perusahaan Gula 30:3-4, 25-29. 
Prescott L, Harley J, Klein DA (1999). Microbiology. McGraw-Hill, Boston.

Rahman MK, Parsons JW (1997). Effects of innoculation with Glomus mosseae, Azorhizobium caulinodans and rock phosphate on the growth of and nitrogen and phosphorus accumulation in Sesbania rostrata. Biology and Fertility of Soils 25:47-52.

Rambelli A (1973). The rhizosphere of mycorrhyzae. In: Marks, G.C. and Kozlowski (eds.) Ectomycorrhyzae, their ecology and phisiology. Academic Press, London, 299-343 pp.

Rao S (1992). Biofertilizers in Agriculture. El Sevier publishing, Amsterdand.

Rokade SM, Patil P (1993). Phosphate solubilizing microorganims. A review. Journal of Maharashtra Agricultural Universities 18(1):93-101.

Roos W, Luckner M (1984). Relationships between proton extrusion and fluxes of ammonium ions and organic acids in Penicillium cyclopium. Journal of General Microbiology 130:1007-1014.

Rouat JW, Katznelson H (1961). A study of the bacteria on the root surface and in the rhizosphere soil of crop plants. Journal of Applied Bacteriology 24:164-171.

Rovira AD (1963). Microbial inoculation of plants. I. Establishment of free-living nitrogen fixing bacteria in the rhizosphere and their effects on maize, tomato, and wheat. Plant and Soil 19:304-314.

Salih HM, Yahya Al, Abdul-Rahem AM, Munam BH (1989). Availability of phosphorus in a calcareous soil treated with rock phosphate or superphosphate as affected by phosphate-dissolving fungi. Plant and Soil 120:181-185.

Sánchez P, Logan T (1992). Myths and Science about the chemistry and fertility of soils in the tropics. In: Lal R, Sanchez P (eds) Myths and science of soils of the tropics. Madison, Soil Science Society of America, 35-46 pp.

Scher FM (1986). Biological control of Fusarium wilts by Pseudomonas putida and its enhancement by EDDA. In: Swinburne T (ed.) Iron, siderophores, and plant diseases. Plenum, New York, 109-117 pp.

Shabayey VP, Smolin VY, Mudrick (1996). Nitrogen fixation and CO2 exchange in soybeans inoculated with mixed cultures of different microorganisms. Biology and Fertility of Soils 24:425-430.

Smith SE, Read DJ (1997). Mycorrhizal Symbiosis. Academic Press, London.

Sreenivasa M, Krishnaraj M (1992). Synergistic interaction between VA mycorrhizal fungi and a phosphate solubilizing bacterium in chili. Zentralblatt fur mikrobiologie 147:126-130.

Stevenson FJ (1986). Cycles of soil. John Wiley and Sons, New York.

Sturtz AV, Christie BR, Matheson BG, Nowak J (1997). Biodiversity of endophytic bacteria which colonize red clover nodules, roots, stems and foliage and their influence on host growth. Biology and Fertility of Soils 25:13-19.

Sylvia D (1999). Mycorrhizal symbioses. In: Sylvia D, Fuhrmann J, Hartel P, Zuberer D (eds) Principles and Applications of Soil Microbiology. Prentice Hall, Upper Saddle River, NJ, 408-426 pp. 
Tinker PB (1980). Role of rhizosphere microorganisms in phosphorus uptake by plants. In: Khasawneh FE, Sample EC, Kamprath EJ (eds) The role of phosphorus in agriculture. Madison, Soil Science Society of America, 617-654 pp.

Toro M, Azcon R, Herrera R (1996). Effects on yield and nutrition of mycorrhizal and nodulated Pueraria phaseolides exerted by P-solubilizing rhizobacteria. Biology and Fertility of Soils 21:2329.

Torsvik V, Salte K, Sorheim R, Goksoyr J (1990). Comparison of phenotypic diversity and DNA heterogeneity in a population of soil bacteria. Appl. Environ. Microbiol 56:776-781.

Turco RF (1994). Microbial indicators of soil quality. In: Doran JW, Coleman DC, Bezdicek DF, Stewart BA (eds) Defining soil quality for a sustainable environment. SSSA and ASA, Madison, 73-90 pp.

Van Peer R, Van Kiuik AJ, Rattin KH, Schippers B (1990). Control of Fusarium wilt in carnation grown on rockwool by Pseudomonas sp. strain WCS417a and by Fe-EDDA. Netherlands Journal of Plant Pathology 96:119-132.

Whipps JM, Lynch JM (1986). The influence of the rhizosphere on crop productivity. Advances in Microbial Ecology 9:187-244.

Whitelaw MA (2000). Growth Promotion of plants inoculated with phosphate-solubilizing fungi. Advances in Agronomy 69:99-151.

Yeates G, Darrah PR (1991). Microbial changes in a model rhizosphere. Soil Biology and Biochemistry 23:963-971.

Young CC, Chen CL, Chao CC (1990). Effect of Rhizobium, vesicular-arbuscular mycorrhiza and phosphate solubilizing bacteria on yield and mineral phosphorus uptake of crops in subtropicaltropical. Transactions 14 th international congress of soil science.

Young R, Davies C (1980). Phosphate fertilizers and process technology. In: Khasawneh FE, Sample E, Kamprath E (eds) The role of phosphorus in agriculture. Soil Science Society of America, Madison, WI, 195-226 pp.

Zuberer DA (1999). Biological dintrogen fixation: introduction and non-symbioti., In: Sylvia D, Fuhrmann J, Hartel P, Zuberer D (eds) Principles and Applications of Soil Microbiology. Prentice Hall, Upper Saddle River, NJ, 295- 321 pp. 